\title{
The Mycobacterium tuberculosis DNA-repair helicase UvrD1 is activated by redox-dependent dimerization via a 2B domain cysteine conserved in other Actinobacteria.
}

Ankita Chadda, Drake Jensen, Eric J. Tomko, Ana Ruiz Manzano, Binh Nguyen, Timothy M. Lohman, and Eric A. Galburt*

Department of Biochemistry and Molecular Biophysics, Washington University in Saint Louis, 660 South Euclid Avenue, Saint Louis, MO, 63110, USA

${ }^{*}$ Corresponding author

Email: egalburt@wustl.edu

Author Contributions: A.C. designed the research, purified proteins, collected and analyzed the data, and wrote the paper. D.J., E.J.T., and B.N. assisted with data collection and analysis. A.R.M. assisted with protein purification, T.M.L. designed the research, assisted with data analysis, and edited the paper. E.A.G. designed the research and wrote the paper.

Keywords: DNA repair, helicases, redox signal, Mycobacterium tuberculosis, UvrD 


\begin{abstract}
Mycobacterium tuberculosis (Mtb) causes Tuberculosis and, during infection, is exposed to reactive oxygen species (ROS) and reactive nitrogen intermediates (RNI) from the host immune response that can cause DNA damage. UvrD-like proteins are involved in DNA repair and replication and belong to the SF1 family of DNA helicases that use ATP hydrolysis to catalyze DNA unwinding. In $M t b$, there are two UvrD-like enzymes where UvrD1 is most closely related to other family members. Previous studies have suggested that UvrD1 is exclusively monomeric, however it is well-known that $E$. coli UvrD and other UvrD-family members exhibit monomer-dimer equilibria and unwind as dimers in the absence of accessory factors. Here, we reconcile these incongruent studies by showing that Mtb UvrD1 exists in monomer, dimer, and tetramer oligomeric forms where dimerization is regulated by redox potential. We identify a 2B domain cysteine, conserved in many Actinobacteria, that underlies this effect. We also show that UvrD1 DNA unwinding activity correlates specifically with the dimer population and is thus titrated directly via increasing positive (i.e. oxidative) redox potential. Consistent with the regulatory role of the $2 \mathrm{~B}$ domain and the dimerization-based activation of DNA unwinding in UvrD-family helicases, these results suggest that UvrD1 is activated under oxidizing conditions when it may be needed to respond to DNA damage during infection.
\end{abstract}

\title{
Introduction
}

DNA repair plays an essential role in the ability of organisms to maintain genome integrity in the face of environmental stresses. One particularly flexible and conserved pathway is Nucleotide Excision Repair (NER) which detects, and repairs bulky nucleotide lesions caused by UV light, environmental mutagens, and a subset of oxidative lesions (1-3). In bacteria, global genome NER is initiated when lesions are recognized directly by UvrA, although an alternative pathway called transcription-coupled NER depends on RNA polymerase stalling as the initiation event (4-7). The removal of the lesion eventually requires the recruitment of a helicase to the site of damage. In Eukaryotes, this function is filled by TFIIH (8-10), while prokaryotes utilize the UvrD-family enzymes $(1,3,11)$. In addition to its role in NER, UvrD participates in a range of other pathways of DNA metabolism such as replication (12-15) and recombination (16-18).

UvrD has been well-characterized in many contexts and from model organisms including $E$. coli and $B$. subtilis. It is a superfamily $1 A$ (SF1A) helicase, as defined by core helicase domains $1 A$ and $1 B$ coupled with auxiliary $2 A$ and $2 B$ sub-domains $(19,20)$. It can both translocate on singlestranded DNA (ssDNA) and unwind double-stranded DNA (dsDNA) under specific conditions. More precisely, while monomers of UvrD-family members (UvrD, Rep and PcrA) are ATP-dependent ssDNA translocases, dimeric forms of these enzymes are required to unwind duplex DNA in vitro in the absence of accessory factors or force (21-27). In Rep, this activation is regulated by the mobile $2 \mathrm{~B}$ domain as both deletion of the $2 \mathrm{~B}$ domain or a crosslinked $2 \mathrm{~B}$ domain construct activate the Rep monomer for unwinding $(28,29)$. Activation of the dimeric UvrD helicase is also accompanied by re-orientation of its $2 \mathrm{~B}$ sub-domain (30). Additionally, the rotational orientation of the $2 \mathrm{~B}$ domain regulates the force-dependent unwinding activity of both UvrD and Rep monomers $(31,32)$. Helicase activation can also occur via binding with accessory factors. For example, $B$. stearothermophilus RepD activates PcrA monomers $(31,32,25)$ and the mismatch repair protein MutL activates UvrD monomers $(33,34)$. Furthermore, these interactions directly affect the orientation of the regulatory $2 \mathrm{~B}$ domain (34). In addition to its association with other repair proteins (32), UvrD associates with RNA polymerase through its C-terminal RNAP Interaction Doman (RID) during one mode of transcription coupled NER (35-37). This interaction leads to the stimulation of RNAP backtracking and the recruitment of UvrAB (37).

While many studies have been reported focusing on UvrD-family helicases from model bacteria, less is known about these enzymes in the distantly related human pathogen, Mycobacterium tuberculosis (Mtb). Mtb is the causative agent of Tuberculosis and is the leading cause of death worldwide from an infectious agent (38). Although DNA metabolism pathways such as transcription and repair are generally conserved in bacteria, important differences exist (39-42). This appears to be especially true in $M t b$, perhaps as it is highly evolved for a relatively narrow niche (43). Interestingly, and in contrast to model bacteria, Mtb contains two UvrD family enzymes: 
UvrD1 and UvrD2 $(44,45)$. UvrD1 has high homology to E. coli UvrD including the C-terminal RID $(45,46)$. Previous work on Mtb UvrD1 has shown that it is important for survival after UV and oxidative damage as well as for pathogenesis in mice (47). In stark contrast to other UvrD-family members, UvrD1 has been reported to be monomeric and to either possess helicase activity directly or require activation via the binding of $M t b \mathrm{Ku}(45,46,48)$.

Here we report that UvrD1 exists in monomer, dimer, and tetrameric forms where dimerization is redox-dependent and is correlated with helicase activity. We identify a $2 \mathrm{~B}$ domain cysteine that is required for the redox-dependent dimerization, demonstrating that the $2 \mathrm{~B}$ subdomain is directly involved in dimerization. Our results explain the function of UvrD1 in the context of the large body of work on UvrD-family proteins and suggest a model where UvrD1 senses the oxidative conditions within human macrophages during infection through dimerization, resulting in activation of its DNA unwinding activity needed for DNA repair and other DNA metabolic pathways (49-51).

\section{Results}

\section{The oligomeric state of UvrD1 is redox-dependent.}

Previous studies reported that UvrD1 exists exclusively as a monomer in solution $(45,48)$. However, upon purifying UvrD1 as described in the Methods, we observed two elution peaks from an S300 size exclusion column run at $4{ }^{\circ} \mathrm{C}$ in Tris pH 8.0 at $25^{\circ} \mathrm{C}, 150 \mathrm{mM} \mathrm{NaCl}, 10 \%$ glycerol, and no DTT, consistent with the molecular weights of both monomer ( $85 \mathrm{kDa})$ and dimer $(170 \mathrm{kDa})$ species (Fig. S1). This result is consistent with studies of $E$. coli UvrD, which exhibits a monomerdimer-tetramer equilibrium $(23,26)$. To examine this more quantitatively, we performed analytical ultracentrifugation sedimentation velocity experiments in TRIS pH 8.0 at $25^{\circ} \mathrm{C}$ and $20 \%$ glycerol (from here on defined as Buffer A) with $75 \mathrm{mM} \mathrm{NaCl}$ and $2.5 \mu \mathrm{M}$ UvrD1. The continuous sedimentation coefficient (c(s)) distribution (52) shows three peaks that we assign to monomer, dimer and higher order oligomers (Fig. 1A, Supplemental Table 1). The positions of the peaks do not change with UvrD1 concentration indicating that each peak represents a single species; however, the amplitudes of the three peaks change with UvrD1 concentration as expected for a self-assembling monomer-dimer-oligomer system (Fig. S2). The oligomeric states of $E$. coli UvrD depend on the salt and glycerol concentrations, with the monomer population favored by higher salt and glycerol concentrations (26). We examined the salt dependence of the UvrD1 oligomeric state by sedimentation velocity at $2.5 \mu \mathrm{M}$ UvrD1 in a range of $\mathrm{NaCl}$ concentrations between 75 $750 \mathrm{mM}$. Surprisingly, the ratio of monomer to dimer was relatively constant throughout the salt titration apart from the lowest salt concentrations where higher order oligomers were populated at the expense of the monomer population (Fig. 1B, S3).

In contrast, the addition of $1 \mathrm{mM}$ DTT at $400 \mathrm{mM} \mathrm{NaCl}$ in Buffer A shifted the species fraction dramatically to favor the monomer (96\%, Fig 1C). Even at the lowest $\mathrm{NaCl}$ concentration of $75 \mathrm{mM} \mathrm{NaCl}$, the addition of $1 \mathrm{mM}$ DTT resulted in a nearly uniform monomer population $(90 \%$, (Fig. S4). Thus, we hypothesized that UvrD1 dimerization is dependent on redox potential and reasoned that oxidative conditions should favor dimer formation just as reductive conditions favor the monomer species. To test this, we performed sedimentation velocity experiments in the presence of oxidizing agents after reduction by $1 \mathrm{mM}$ DTT. As predicted, titration of hydrogen peroxide $\left(\mathrm{H}_{2} \mathrm{O}_{2}\right)$ resulted in an increase in the dimer population (Fig. 1D, S5). At $2 \mathrm{mM} \mathrm{H}_{2} \mathrm{O}_{2}$, the population fraction of dimer saturated at $\sim 25 \%$ and the addition of more hydrogen peroxide did not lead to more dimer formation. 



Figure 1: Oligomeric states of UvrD1. (A) Sedimentation velocity trace measured at $230 \mathrm{~nm}$ in Buffer A plus $75 \mathrm{mM} \mathrm{NaCl}$ in the absence of DTT reveals the presence of monomeric, dimeric, and tetrameric species. (B) Summary of results from AUC velocity experiments using $2.5 \mu \mathrm{M}$ UvrD1 in the absence of DTT as a function of NaCl concentration (Fig. S3). From $75 \mathrm{mM}$ to $750 \mathrm{mM} \mathrm{NaCl}$, the fraction of monomer present in the monomeric state (blue), dimeric state (red), and tetrameric states (yellow) are shown. (C) The continuous distribution of species from AUC velocity runs measured at 280 $\mathrm{nm}$ with $400 \mathrm{mM} \mathrm{NaCl}$ in the presence and absence of $1 \mathrm{mM} \mathrm{DTT}$. (D) After treatment of $2.5 \mu \mathrm{M}$ WT UvrD1 in $75 \mathrm{mM}$ $\mathrm{NaCl}$ with $1 \mathrm{mM}$ DTT, a titration series of $\mathrm{H}_{2} \mathrm{O}_{2}$ from $\mathrm{O} \mathrm{mM}$ to $5 \mathrm{mM}$ was run in AUC velocity experiments (Fig. S5). Increasing concentrations of $\mathrm{H}_{2} \mathrm{O}_{2}$ result in a decrease in the fraction found in the monomeric state (blue) and an increasing fraction found in the dimeric state (red). Higher order oligomeric states (yellow) represented less than $10 \%$ under all conditions.

\section{A 2B domain-2B domain disulfide bond is responsible for redox-dependent dimerization of $\underline{\text { UvrD1 }}$ \\ The dependence of oligomerization on oxidation suggested a role for a thiol-containing} amino acid such as methionine or cysteine. In particular, we considered that the potential of cysteines to form disulfide bonds could lead to the formation of dimeric and higher order oligomers. UvrD1 has three cysteine residues for which we estimated their approximate position by generating a threaded homology model of UvrD1 based on the structure of $E$. coli UvrD (PDB:3LFU, PHYRE2, Methods, Fig. 2A). This model shows that, while two cysteines appear buried within the $1 \mathrm{~A}$ and $1 \mathrm{~B}$ domains (C107 and C269), a third cysteine (C451) is surface exposed within the 2B domain. Surface calculations of our model with Chimera (53) confirmed this as only C451 possesses solvent exposed surface area in both open (based on E. coli PDB:3LFU structure) and closed (based on G. stearothermophilus PDB:3PJR structure) conformations (Fig. S6). We hypothesized that a 
disulfide bond between the $2 \mathrm{~B}$ cysteines of two monomers was responsible for the redoxdependent dimerization. To test this, we constructed and purified a C451A mutant (which will we refer to as the $2 \mathrm{~B}$ mutant) and examined whether it is able to form dimers. During purification of this construct, the $\mathrm{S} 300$ elution profile showed only a single peak consistent with a monomer in contrast to WT UvrD1 (Fig. 2B). Sedimentation velocity experiments confirmed this result, as the 2B cysteine mutant was monomeric in both the presence and absence of DTT (Fig. 2C, Supplemental Table 1). In contrast, a double mutant of the $1 \mathrm{~A}$ and $1 \mathrm{~B}$ domain cysteines (C107T/C269T, now referred to as the 1A1B double mutant) maintained the ability to form dimers (Fig. 2D, Supplemental Table 1).

The three cysteine residues found in UvrD1 are not conserved in E. coli UvrD, despite the presence of six cysteine residues (Fig. 3A), and E. coli UvrD does not display a redox-dependent dimerization (Fig. S7). However, the 2B domain cysteine identified here is conserved across various Actinobacterial classes (Fig. 3B,C, S8). A particularly high, but not universal, conservation was found in the Corynebacteriales order which includes Mtb and other pathogenic bacteria (54, 55). In addition, we found the same sequence in the PcrA helicase found in one strain of the Firmicute, Clostridioides difficile (NCTC13750), which represents another important human pathogen that interacts with macrophages $(56,57)$.
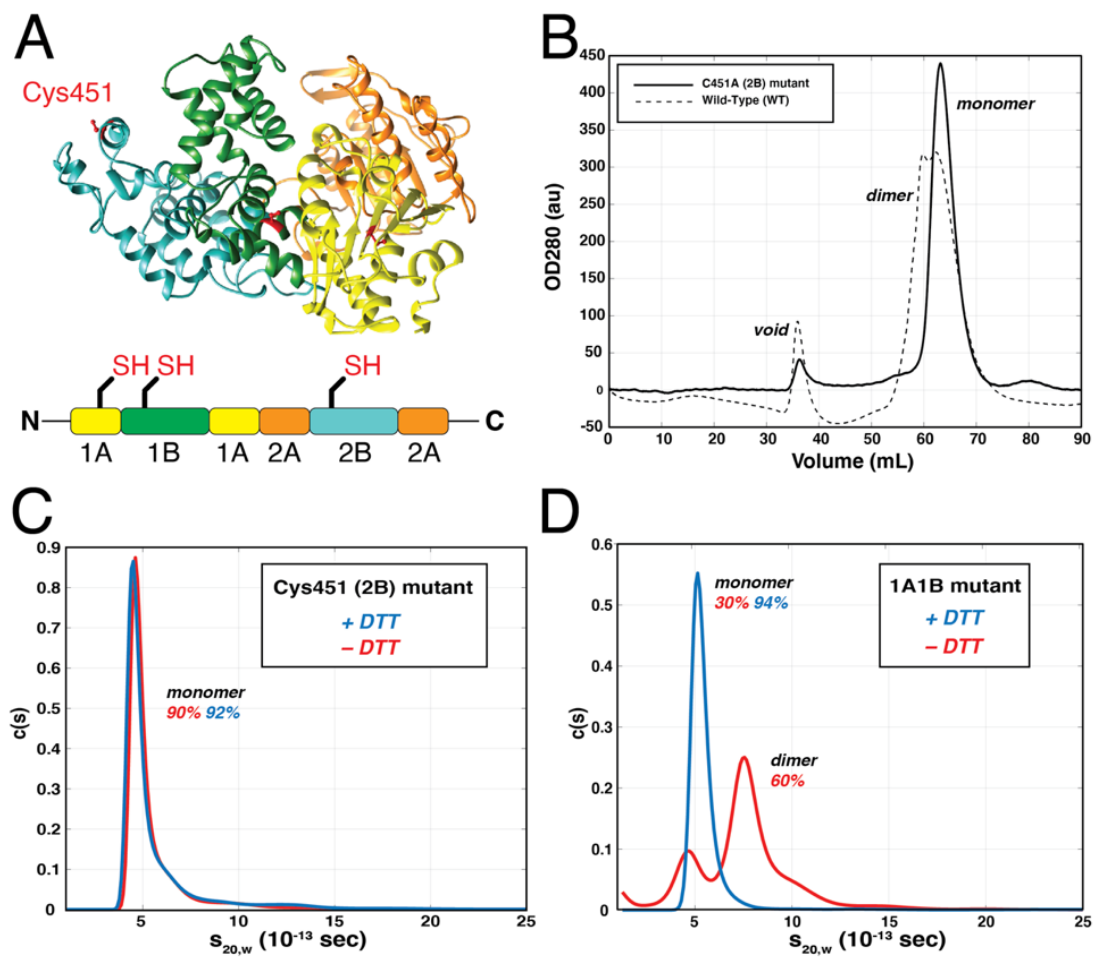

Figure 2: Redox-Dependence of UvrD1 dimerization is due to C451 in the 2B domain. (A) Predicted structure of UvrD1 from threading UvrD1 sequence on the E. coli UvrD structure (PDB: 3LFU). Domain organization is indicated as well as the position of the three cysteine residues described in the text. (B) Size exclusion chromatography (S300) of C451A


the absence of DTT as in Fig. S1. (C) AUC velocity experiments on the $2 B$ mutant in Buffer A plus $75 \mathrm{mM} \mathrm{NaCl}$ and the presence (blue) and absence (red) of DTT indicate that the mutant loses the ability to dimerize. Each trace is an average of two runs and the population fractions for monomer and dimer are indicated. (D) In contrast, AUC velocity of the $1 A 1 B$ double mutant in $75 \mathrm{mM} \mathrm{NaCl}$ and the presence (blue) and absence (red) of $1 \mathrm{mM}$ DTT indicates that this mutant retains and even enhances dimer formation. Each trace is an average of two runs and population fractions for monomer and dimer are indicated. 


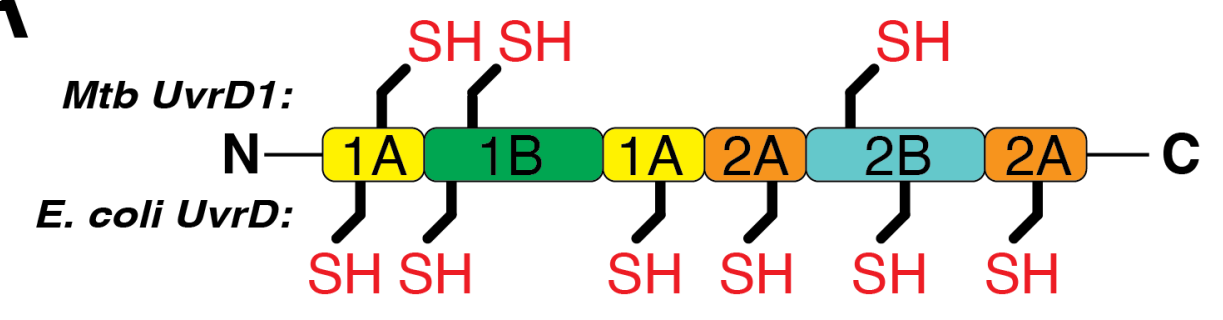

B

add order headings

E. Coli UvrD

E. coli Rep

B. subtilis PcrA

M. tuberculosis UvrD1

C. difficile PcrA

G. bronchialis UvrD

D. cinnamea UvrD

T. paurometabola PcrA

H. rhizosphaerae PcrA

T. cavernea UvrD

M. ulcerans PcrA

R. hoagii PcrA

S. regensis PcrA

S. nassauensis PcrA

A. thailandica PcrA

L. tulufanense PcrA

A. pittospori PcrA

T. lapilli PcrA

A. logoneensis PcrA
EIKDALSYLRLIANRNDDAAFERVVNTPTRGIGDRTLDVVROTSR 431 EIKDLLAYLRVLTNPDDDSAFLRIVNTPKREIGPATLKKLGEWAM 426 EIKDILAYLRLVSNPDDDISFTRIVNVPKRGVGATSLEKIASYAA 435 EIRDIVAYLRVLDNPGDAVSLRRILNTPRRGIGDRAEACVAVYAE 457 EVRDVVAYLRVVANPDDSVSLRRILNTPRRGIGDRAEACVAVHSE 473 EVRDVVAYLRVVANPDDAVSLRRILNTPRRGIGDRAEACVAVHSE 468 EVRDVVAYLKVLNNPDDAVAIRRILNTPRRGIGDRAEACVVVHAE 462 EVRDLVAYLRAIDNPNDTVSLQRIVNTPRRGIGDRAQACLTVHAE 471 EVRDIVAYLRVLANPDDAVSLRRILNTPRRGIGDRAEACVSVHAE 495 EIRDVVAYLRVLLNEEDTVSVRRILNTPRRGIGDRAEACVSVHAE 502 EIRDIVAYLRVLDNPGDAVSMRRILNTPRRGIGDRAEACVAVYAE 452 EVRDIVAYLRVLANEDDTVSLRRILNTPRRGIGDRAEACVSVYAE 470 EVRDIVAYLRVLENPDDAVSMRRILNTPRRGIGDRAEACVAVHAE 509 EVRDALAYLRLTVNEDDIVSGRRVVNVPKRGIGDRAVACVDALAD 453 EVRDALAYLRAIANPDDVVSVRRILNTPRRGIGERAEACVDALAS 480 EVRDALAYLRVLDNPEDTVSLRRILNVPKRGIGDRAEACVAAHAE 478 EVRDALAYLRLLANPEDTVSLRRILNVPKRGIGDRAEACVEAFAQ 456 EVRDALAYLRVISNPTDTVNLRRILNTPKRGIGDRAEACVAALAE 441 EVRDLLAYLRVLANPEDTVSLRRILNVPKRGIGDRAEACVEAYAS 441


Figure 3: Sequence distribution across bacterial species. (A) Distribution of cysteine residues in Mtb UvrD1 compared to $\mathrm{E}$. coli UvrD. (B) Sequence alignment of the $2 B$ domain region containing $C 451$. The blue sequence is conserved across all UvrD-like family members while the sequence containing $2 B$ cysteine residue (red) is distinct from $\mathrm{E}$. coli and $\mathrm{B}$. subtilis UvrD family enzymes but conserved in many Actinomycetes. See Supplemental information for full species names. (C) Orders and Families of Actinobacteria where the 2B cysteine can be found in available sequence data. 


\section{The dimer of UvrD1 is required for DNA unwinding activity.}

Previous studies of UvrD1 suggested that the monomer possesses helicase activity (48). However, this conclusion was based on measurements of helicase activity performed in solution conditions distinct from those used to examine its oligomerization state. In particular, the analysis of oligomeric state was performed in the presence of $5 \mathrm{mM}$ DTT while helicase assays were performed in buffer lacking DTT entirely (48). In other studies, UvrD1 was surmised to be a monomer based on sedimentation through a glycerol gradient and was reported to have unwinding activity that was dramatically activated in the presence of $M$ tb $\mathrm{Ku}(45)$.

Given the observations of other UvrD-family helicases $(23,25,26,28,58)$, we hypothesized that only the dimer of UvrD1 would be capable of unwinding DNA. To test this hypothesis, we used a stopped-flow assay to measure the time-dependence of UvrD1-catalyzed DNA unwinding (Fig. 4A). Specifically, we used a double-stranded 18 bp DNA with a singlestranded $\mathrm{dT}_{20} 3^{\prime}$ flanking region (tail), with a Cy5 fluorophore on the 5 ' end of the tailed strand, and a black hole quencher (BHQ2) on the 3' end of the complementary strand as described previously $(33,34)$. In the double-stranded form, fluorescence from Cy5 is quenched due to the presence of the BHQ2 (59). Upon full unwinding, the strands are separated and the BHQ2 strand is trapped via an excess of unlabeled complementary "trap" DNA resulting in an increase in Cy5 fluorescence. This excess of trap also serves to bind any UvrD1 that dissociates from the labeled template ensuring single-round turnover conditions (Fig. S9A). UvrD1 was pre-bound to the labeled DNA template and was loaded in one syringe. This solution was rapidly mixed with the contents of the other syringe consisting of an excess of trap strand, $5 \mathrm{mM} \mathrm{Mg}^{+2}$, and $1 \mathrm{mM} \mathrm{ATP}$. The fraction of DNA unwound as a function of time was calculated by comparing experimental traces to a positive control consisting of fully single-stranded Cy5-labeled DNA and a negative control in the absence of ATP (Fig. S9B).

In the absence of reducing agent, $200 \mathrm{nM}$ WT UvrD1 can unwind $\sim 27 \%$ of $2 \mathrm{nM}$ duplex DNA in a single-round reaction (Fig. 4B, red) consistent with the fraction dimer in these conditions (Fig. 1A). In addition, the kinetics and final percent unwound show a duplex-length-dependence as is expected (Fig. S10A). Fits to an n-step model with a non-productive fraction (Fig. S10A,B) lead to an average unwinding rate of $64.8 \pm 6.4 \mathrm{bp} / \mathrm{s}$ (Supplemental Table 2). Similarly, a lag time analysis $(60,61)$ yielded an estimate of the unwinding rate of $83.3 \pm 12.3 \mathrm{bp} / \mathrm{s}$ (Fig. S10C,D). In contrast, in the presence of $1 \mathrm{mM}$ DTT, which shifts the UvrD1 population to favor monomers, no unwinding is observed consistent with the UvrD1 dimer being required for unwinding activity (Fig. 4B, blue). In addition, the 2B mutant ( $451 \mathrm{~A})$, which we have shown is an obligate monomer even under oxidative conditions, lacks helicase activity in both the presence and absence of DTT (Fig. 4C, cyan and purple). Consistently, the 1A1B double mutant is still able to unwind DNA in the absence of DTT (Fig. 4C, pink). In fact, the 1A1B double mutant unwinds a higher fraction of DNA compared to WT $(\sim 63 \%)$, consistent with the AUC results suggesting that a higher fraction of the enzyme is in the dimeric form in the absence of DTT (Fig. 2D). Thus, the dimer fraction of UvrD1 formed via the $2 \mathrm{~B}$ domain disulfide bond is required for DNA unwinding activity. 
A

SYRINGE 1:

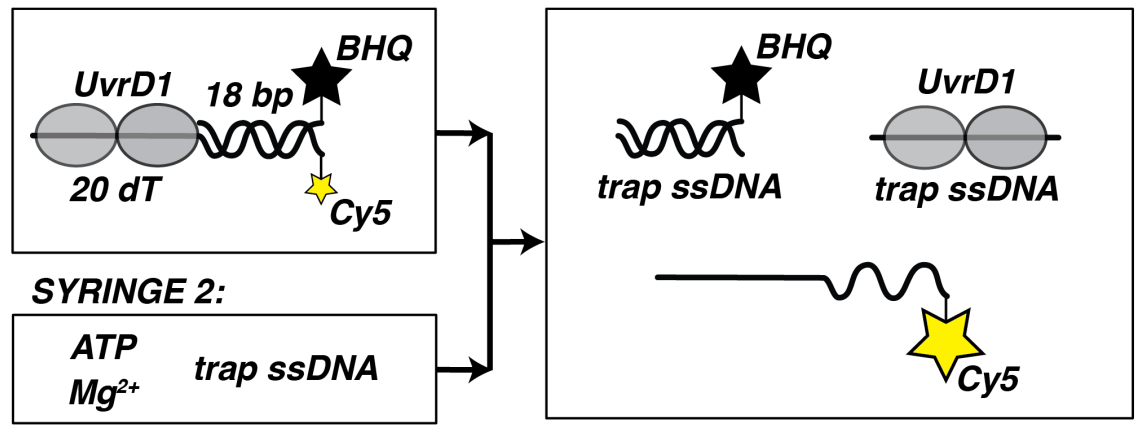

B

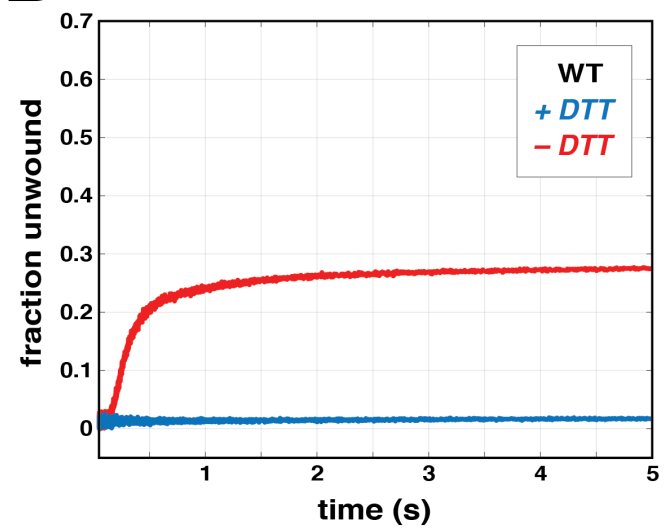

OBSERVATION CELL:
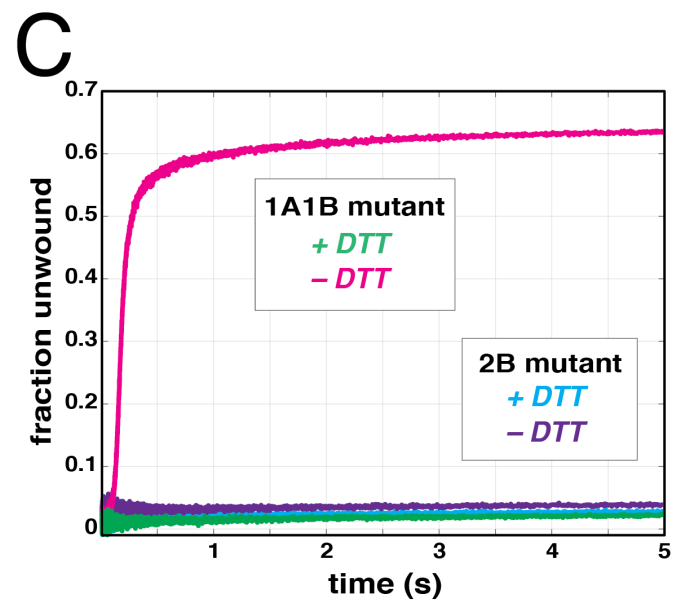

Figure 4: Unwinding activity is dependent on redox-dependent dimer. (A) Stopped-flow assay for monitoring DNA unwinding. One syringe is filled with UvrD1 that has been pre-equilibrated with a fluorescently labeled unwinding template consisting of an 18 bp duplex with a 3' single-stranded 20 dT tail. The 5' end of the loading strand is labeled with Cy5 and the 3' end of the other strand is labeled with a black hole quencher (BHQ). A second syringe is filled with ATP, $\mathrm{Mg}^{2+}$, and single-stranded trap DNA. Upon mixing UvrD1 unwinds some fraction of the DNA resulting in a fluorescence enhancement due to the separation of the Cy5 from the BHQ. The excess trap DNA binds both the BHQ labeled single-strand and any free UvrD1 to establish single-round turnover conditions. (B) Fraction of DNA template unwound with $200 \mathrm{nM}$ wild-type UvrD1 in the presence (blue) and absence (red) of DTT. (C) Fraction of DNA template unwound with $200 \mathrm{nM} 1 \mathrm{A1B}$ double and 2B mutants of UvrD1 in the presence (green and cyan) and absence (pink and purple) of DTT in Buffer A with $75 \mathrm{mM} \mathrm{NaCl}$.

\section{Both monomers and dimers of UvrD1 bind DNA}

When considering why UvrD1 dimerization is required for DNA unwinding, we initially considered two hypotheses. One was that monomers are unable to bind DNA at the concentrations utilized and the second was that dimerization is required for helicase activation. To determine the nature of the DNA-bound species, we used sedimentation velocity to examine both WT UvrD1 and the $2 \mathrm{~B}$ mutant in the absence of reducing agent and in the presence of fluorescently labeled $18 \mathrm{bp}$ $\mathrm{dT}_{20}$ DNA. The results show that both monomers and dimers interact with the DNA and appear to bind the DNA in the same ratio as the free oligomeric forms. Specifically, in the presence of $1.5 \mu \mathrm{M}$ WT UvrD1 and $1.5 \mu \mathrm{M}$ DNA, $30 \%$ of the DNA was bound by monomers and $31 \%$ was bound by dimers (Fig. 5A, red, Supplemental Table 3). In the presence of $1.5 \mu \mathrm{M}$ of the $2 \mathrm{~B}$ mutant, only monomers were bound to DNA (Fig. 5A, blue). Even at higher molar ratios of monomeric UvrD1 (i.e., the 2B mutant) to DNA, only monomers are observed bound to DNA suggesting that DNA binding alone does not stimulate dimerization (Fig. S11). In contrast, when WT UvrD1 in the 
absence of DTT is mixed with DNA possessing a shorter single stranded extension ( $\left.\mathrm{dT}_{10}\right)$, only monomers bind (Fig. 5B, Supplemental Table 3) and no DNA unwinding is observed (Fig. S12). This result is consistent with a model where each individual monomer interacts with the ssDNA in the context of the bound dimer as is seen with E. coli UvrD (23). Fluorescent anisotropy experiments with the unwinding substrate DNA (18 bp dT 20 ) and either WT or 2B mutant UvrD1 yielded similar concentration dependencies of binding, consistent with the idea that the affinities of the monomeric and dimeric species are similar (Fig. 5C).

The observation of DNA-bound monomers directly eliminates the possibility that monomers do not unwind because they do not bind DNA and suggests that some other property of the dimer is required for unwinding. This is consistent with other studies of UvrD-family enzymes as described in the Discussion.

At a constant redox potential established by the addition of $2 \mathrm{mM} \mathrm{H}_{2} \mathrm{O}_{2}$, the expected protein-concentration dependence of DNA unwinding is observed (Fig. 5D). Here, the fraction of DNA unwound saturates at $\sim 27 \%$ consistent with the fraction of dimers under these conditions (Fig. 1D) further suggesting that the monomers and dimers compete approximately equally for this DNA substrate under these conditions.
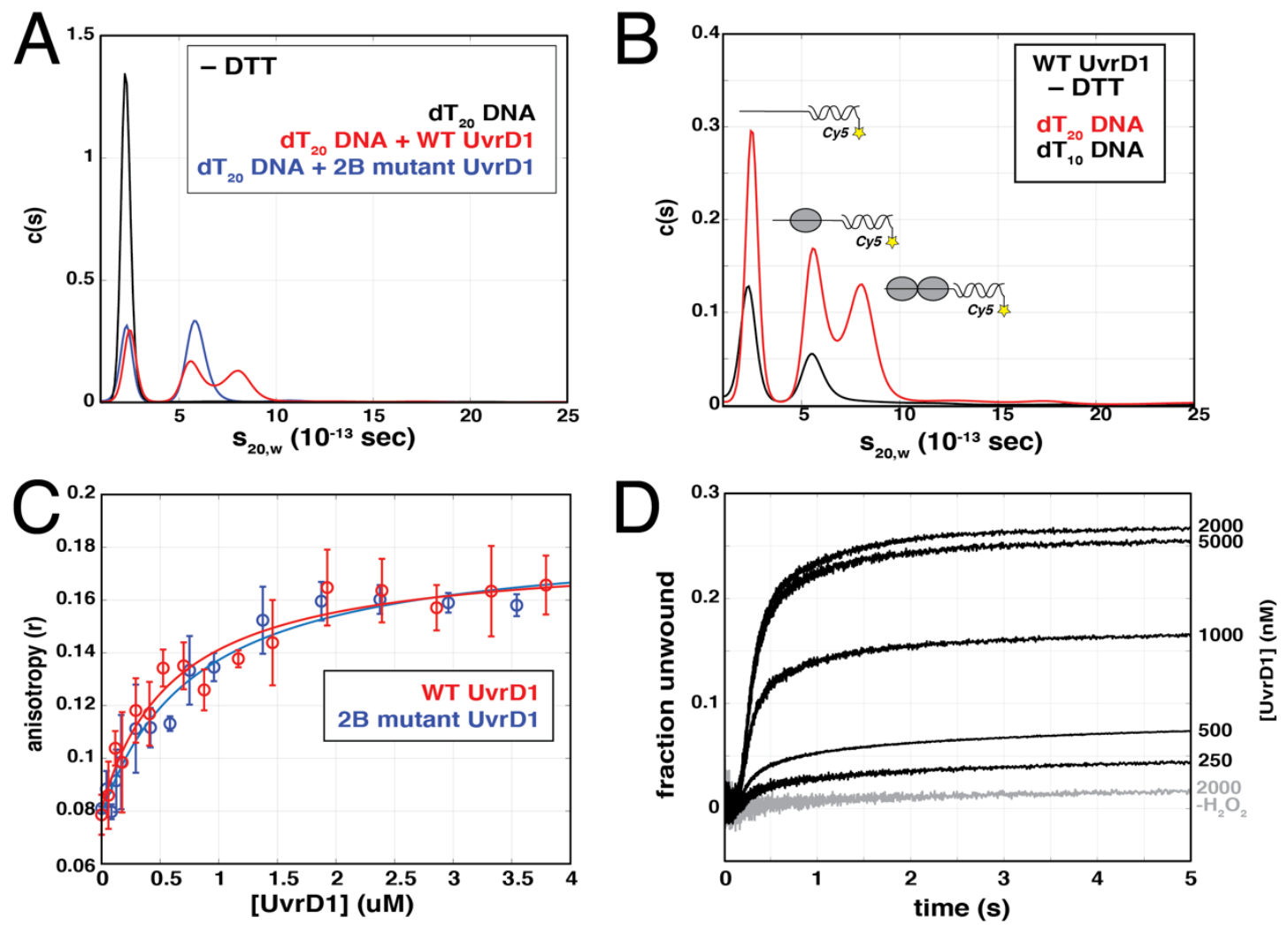

Figure 5: Monomer and dimer forms of UvrD1 both bind DNA unwinding template. (A) All experiments were performed in Buffer A with $75 \mathrm{mM} \mathrm{NaCl}$. A Cy5-labeled DNA was used in sedimentation velocity experiments to specifically interrogate DNA-bound species. $d T_{20}$ DNA alone (black), DNA and wild-type UvrD1 in the absence of reducing agent (red), and DNA and the $2 B$ mutant in the absence of reducing agent (blue) are shown along with the bound species represented by each peak. (B) WT UvrD1 in the absence of reducing agent bound to $d T_{20}$ and $d T_{10} D N A$ templates. Both monomers and dimers bind $d T_{20}$ (red) while only monomers bind $d T_{10}$ (black). (C) Fluorescent anisotropy of a FAM labeled helicase template DNA (dT20 ssDNA tail with 18bp duplex) as a function of UvrD1 concentration. In the absence of DTT, both WT UvrD1 (red) and the 2B mutant (blue) displayed similar concentration dependencies of binding suggesting that they bind this template with similar affinity. (D) DNA unwinding traces as a function of UvrD1 concentration first treated with $1 \mathrm{mM} \mathrm{DTT}$, followed by the addition of $2 \mathrm{mM} \mathrm{H}_{2} \mathrm{O}_{2}$. A control in the absence of oxidizing agent is shown for comparison $\left(-\mathrm{H}_{2} \mathrm{O}_{2}\right)$. 


\section{Both UvrD1 monomers and dimers are single-stranded DNA translocases}

As both monomers and dimers can bind to the DNA substrate (Fig. 5), we considered our second hypothesis that postulated that monomers are unable to translocate along single-stranded DNA thus preventing helicase activity. To test this, we examined the translocation kinetics of UvrD1 on ssDNA. Since UvrD1 has a 3' to 5' DNA unwinding polarity, the kinetics of translocation were measured via stopped-flow assays $(62,63)$ by monitoring the arrival of UvrD1 at the $5^{\prime}$-end of a series of Cy3 5'-end-labeled oligodeoxythymidylate ssDNAs of different lengths $(L=20,35,45,75$, and 104 nucleotides) (Fig. 6A). Arrival of a translocating protein at the 5 '-end results in an enhanced Cy3 fluorescence and subsequent dissociation of UvrD1 leads to a return of the signal to baseline. A heparin concentration of $1 \mathrm{mg} / \mathrm{ml}$ was added to prevent rebinding of free UvrD1 to the ssDNA, ensuring single-round conditions (Fig. S13A). In addition, negative controls in the absence of ATP showed no change in fluorescence (Fig. S13A) and experiments containing ATP and UvrD1 in the presence of 3'-labeled DNA showed only a decay in fluorescence consistent with translocation away from the dye (Fig. S13B). In conditions favoring dimeric UvrD1, the presence of ATP resulted in the expected length-dependent peaks of fluorescence indicative of UvrD1 translocation in the 3' to 5' direction (62,63) (Fig. S14). However, monomeric UvrD1 generated either by the addition of DTT or the use of the 2B mutant also resulted in DNA-length-dependent changes in the fluorescence signal consistent with 3' to 5' ssDNA translocation (Fig. 6B,C). Global analysis using an n-step sequential model (Fig. S15) $(62,64)$ produced better fits for the 2B mutant data possibly because the WT UvrD1 still contains trace amounts of dimer. (Methods and Fig. S16) However, fits of both data sets yielded consistent estimates of the macroscopic translocation rate $(\mathrm{mk} t)$ of $120 \pm 5 \mathrm{nt} / \mathrm{sec}(\mathrm{WT}+\mathrm{DTT})$ and $130 \pm 10 \mathrm{nt} / \mathrm{sec}$ (2B-DTT) for monomeric UvrD1 which is very similar to the ssDNA translocation rate measured for $E$. coli UvrD monomers $(62,63)$. In addition, the estimated dissociation rate $\left(k_{d}\right)$ from the fitting analysis $\left(4.1 \pm 0.1 \mathrm{~s}^{-1}\right)$ was on the same order of magnitude as that obtained by experimentally measures $\left(8.1 \pm 0.2 \mathrm{~s}^{-1}\right)$ (Fig. S16). Other fit parameters are listed in Supplemental Table 4 (64).

The time-courses exhibited under monomeric UvrD1 conditions were distinct from those collected under oxidative conditions suggesting that the monomer and dimer populations exhibit distinct translocation kinetics (Fig. 6B,C, and Fig. S14). Fits using the percent fraction of monomeric and dimeric species and the translocation parameters obtained under monomeric conditions resulted in estimates for the ssDNA translocation properties of the UvrD1 dimer (Supplemental Table 4). Although analysis of the mixed dimer/monomer population was challenging due to the presence of multiple species and kinetic phases, taken together thedata unequivocally show that both monomeric and dimeric UvrD1 translocate with 3' to 5' directionality along ssDNA. 

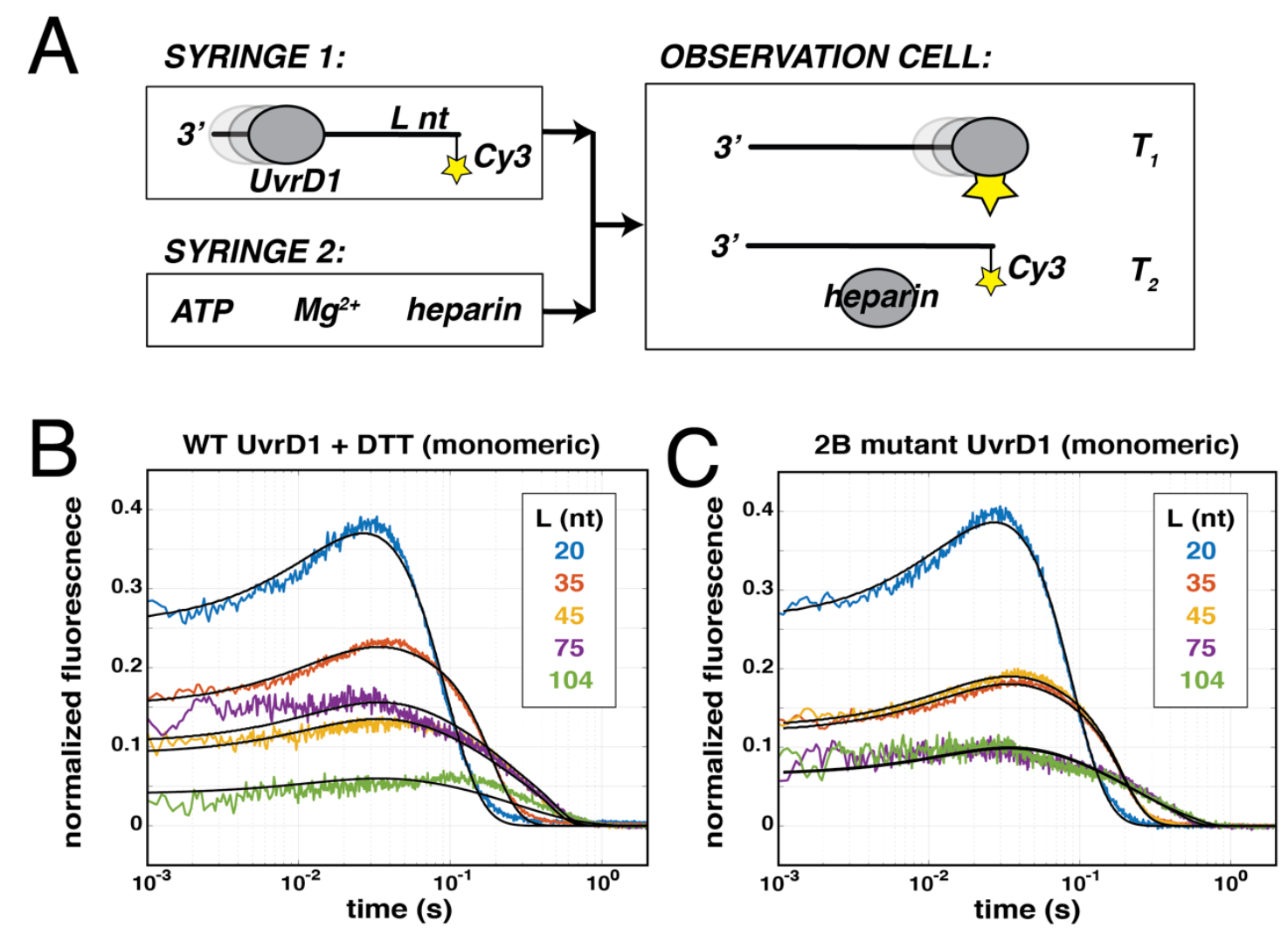

Figure 6: Monomeric UvrD1 translocates on single-stranded DNA. (A) The stopped-flow translocation assay. UvrD1 is allowed to equilibrate and bind to SsDNA templates of different lengths (L). These templates are labeled a the $5^{\prime}$ end with Cy3. The protein DNA solution is mixed with buffer containing ATP, $\mathrm{Mg}^{2+}$, and heparin to stimulate a single round of translocation. As the protein passes the label, the fluorescence increases (T1). As it dissociates, the fluorescence decreases, and free protein is bound by heparin (T2). (B) WT UvrD1 in the presence of 1 mM DTT produces traces consistent with translocation. The peak broadens and moves to longer times with increasing template lengths. (C) Monomeric UvrD1 generated by use of the $2 B$ mutant, also shows clear peaks consistent with translocation. In both (B) and $(C)$ experiments were conducted in Buffer $A$ with $75 \mathrm{mM} \mathrm{NaCl}$, where the traces were normalized to the average of 10 final plateau values observed in the raw data at each DNA length. Fits to an $n$-step sequential stepping model are shown in solid lines.

\section{DNA unwinding activity is titrated by redox potential through dimer formation}

We have shown that UvrD1 dimerization can be titrated via the addition of an oxidizing agent such as $\mathrm{H}_{2} \mathrm{O}_{2}$ (Fig. 1D). Furthermore, these dimers are, in the absence of other activators, required for DNA unwinding (Fig. 4). To determine the quantitative relationship between dimer fraction, DNA unwinding, and redox potential in millivolts $(\mathrm{mV})$, we performed both sedimentation velocity and helicase assays using $\mathrm{H}_{2} \mathrm{O}_{2}$ to titrate redox potential. The $1 \mathrm{~A} 1 \mathrm{~B}$ double mutant was used for these titrations to ensure that any effects stemmed directly from the cysteine in the $2 \mathrm{~B}$ domain. We tested two different concentrations $1 \mu \mathrm{M}$ and $2 \mu \mathrm{M} 1 \mathrm{~A} 1 \mathrm{~B}$ double mutant in the presence of $1 \mathrm{mM}$ DTT which results in over 95\% monomer (Fig. 2D) and shows no DNA unwinding (Fig. 4C). We then titrated $\mathrm{H}_{2} \mathrm{O}_{2}$ from $0-5 \mathrm{mM}$ which corresponds to redox potentials between -270 to $130 \mathrm{mV}$. As the redox potential became more positive (oxidizing), the fraction of DNA unwound increased (Fig. 7, S17 purple). As in the case of the WT UvrD1 (Fig. 1D), the fraction of UvrD1 1A1B double mutant dimer also increased with increasing $\mathrm{H}_{2} \mathrm{O}_{2}$ (Fig. 7, orange). In fact, there is a quantitative correlation between the fraction of DNA unwound and the fraction of UvrD1 mutant dimer, consistent with the hypothesis that UvrD1 helicase activity is stimulated via increasing positive redox potentials found under oxidative conditions (Fig. 7 and Fig. S17). 


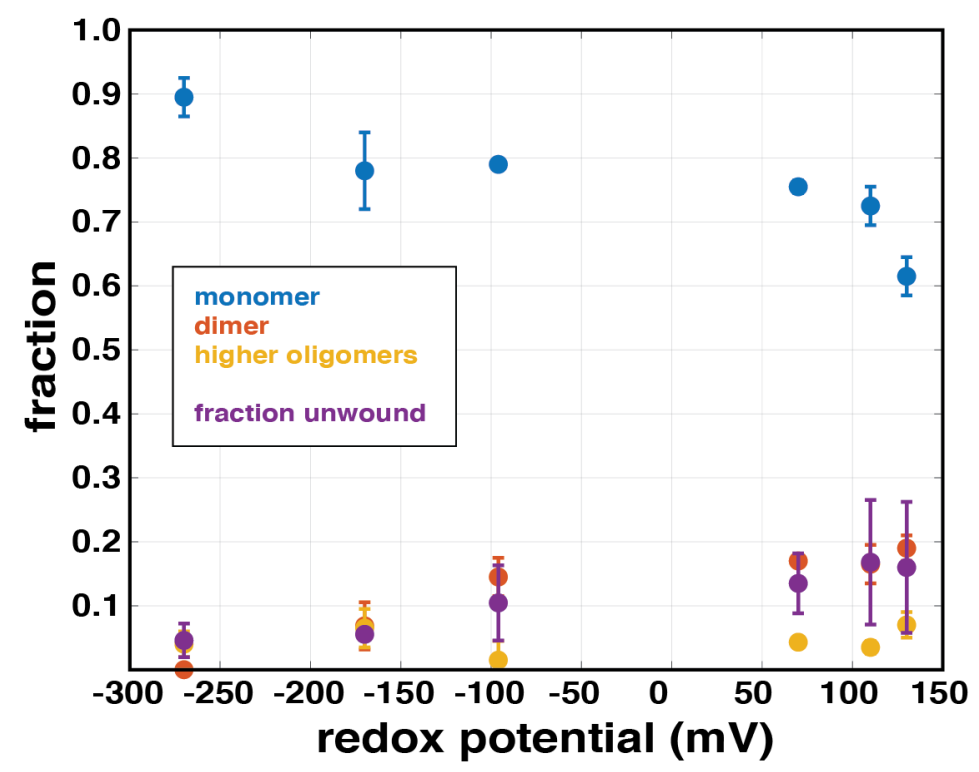

Figure 7: Unwinding activity correlates with dimer fraction and is titrated by redox potential. $1 \mu M$ 1A1B double mutant UvrD1 was dialyzed in Buffer A at $75 \mathrm{mM} \mathrm{NaCl}$, treated with $1 \mathrm{mM} \mathrm{DTT}$, and then incubated with varying concentrations of $\mathrm{H}_{2} \mathrm{O}_{2}$ (0-5 mM). Redox potential was measured and the samples were subject to AUC and used for DNA unwinding assays. The fraction of monomer present in different oligomeric states and fraction DNA unwound are plotted as a function of redox potential as follows: monomer (blue), dimer (orange), higher oligomers (yellow), and fraction DNA unwound (purple).

\section{Discussion}

DNA helicases are enzymes that couple ATP binding and hydrolysis to translocation on ssDNA and unwinding of double-stranded DNA and are involved in critical pathways throughout nucleic acid metabolism. The SF1 superfamily of helicases is the largest group of known helicases and includes UvrD, Rep and PcrA $(19,20)$. These helicases consist of two RecA-like domains (1A and $2 \mathrm{~A}$ ) and two accessory sub-domains (1B and $2 \mathrm{~B})(19,20)$. Studies of SF1 helicases have shown that in the absence of accessory factors or force exerted on the DNA, monomers possess ssDNA translocase activity, but not helicase activity; helicase activity requires at least a dimeric form of the enzyme. $(21,22,27,28,30,32,33,62-64)$ Yet, the dimerization interface is not known as crystal structures of UvrD and PcrA only reveal a monomer bound to DNA (65-68).

Previous studies of Mtb UvrD1 concluded that it is monomeric as shown by size exclusion chromatography (SEC) and equilibrium sedimentation and is capable of unwinding dsDNA in this form $(45,48)$. However, in one case, SEC and equilibrium sedimentation were performed in the presence of the reducing agent DTT, whereas DNA unwinding assays were performed in its absence (48). In the other case, helicase activity of UvrD1 was attributed to monomers and was dependent on its binding partner, $\mathrm{Ku}(45)$. When we purified Mtb UvrD1 without reducing agent it eluted as two peaks on SEC corresponding to the expected molecular weights of both monomer and dimer (Fig. 1A). AUC experiments show that, while salt concentration had almost no effect on the amount of the dimeric form, the addition of DTT results in a dramatic shift to a single monomeric peak suggesting that Mtb UvrD1 undergoes a cysteine dependent dimerization (Fig. 1). We also observe a higher oligomeric species increasing in a concentration dependent manner in sedimentation velocity experiments performed under oxidizing conditions. We do not observe Mtb UvrD1 tetramer binding to the tailed construct used in our unwinding assays (Fig. 5A), but we 
cannot eliminate the possibility that the tetrameric form could bind to DNA possessing longer singlestranded tails.

We identified a critical cysteine residue in the 2B domain of UvrD1 (C451) that is required for UvrD1 dimerization (Fig. 2). More specifically, the C451A mutation abrogated both dimerization and helicase activity pointing to the existence of a $2 \mathrm{~B}-2 \mathrm{~B}$ disulfide bonded dimer. The $2 \mathrm{~B}$ domain of UvrD-like helicases has been described as an auto-inhibitory domain $(28,32)$ that can adopt a range of rotational conformational states relative to the rest of the protein $(28,32,66)$. The different 2B domain conformational states of the monomer are influenced by salt concentration, DNA binding, enzyme dimerization and the binding of accessory protein factors $(26,34,69,70)$. For example, crystal structures of Rep bound to ssDNA showed Rep monomer bound to DNA in two different conformations (66). In one of the conformations the $2 \mathrm{~B}$ domain is in an "open" conformation, while in the other, the $2 \mathrm{~B}$ domain is reoriented by a $130^{\circ}$ swivel motion around a hinge region to contact the $1 \mathrm{~B}$ domain. This swiveling motion closes the binding groove located between 1A, 1B, and 2A domains around the DNA template. Consistently, single molecule and ensemble FRET studies have also shown that the $2 \mathrm{~B}$ domain of a monomer can be in closed or open conformations $(31,34,69-71)$. Furthermore, removing the 2B domain from Rep causes the Rep monomer to gain helicase activity (32). These observations and others have led to the hypothesis that the $2 \mathrm{~B}$ domain serves as the interface between subunits within the functional Rep and UvrD dimers $(19,28,30,72)$.

The formation of a 2B-2B disulfide bond in the case of Mtb UvrD1 fits well in a model where 2B-2B driven dimerization results in an active helicase conformation. Further support for this idea can be found in the specific location of $\mathrm{C} 451$. Mutations to $2 \mathrm{~B}$ domain threonine residues such as T426 of $B$. stearothermophilus PcrA and T422 of E. coli UvrD disrupt helicase activity (73). This threonine residue is conserved in non-Actinobacteria UvrDs, is absent from UvrD-like proteins containing the cysteine residue described here and is located 2 amino acids upstream to the C451 of Mtb UvrD1. The similar location of these residues suggests that UvrD-like helicases share a common 2B-2B dimerization interface and that mutating this threonine destabilizes the dimeric form of the enzyme. Interestingly, the 2B domains of the SF1 family members RecB and RecC interact in a RecBCD helicase complex (74). We aligned the UvrD1 2B domain sequence with the 2B domain sequences of $E$. coli $\operatorname{RecB}$ and RecC which lack a 2B cysteine equivalent to $C 451$. When we mapped residues that aligned close to the $2 \mathrm{~B}$ cysteine onto the structure of RecBCD (PDB:5LD2) $(74,75)$, we observed that these regions in RecB and RecC are only $10-15 \AA$ apart. Again, this is consistent with our identification of the region surrounding the 2B cysteine of UvrD1 as an interface for 2B-2B domain-based activation of UvrD1-like helicases.

As noted, the 2B cysteine we have identified in Mtb UvrD1 appears unique to certain classes of Actinobacteria (Fig. 3). The 2B domain of E. coli UvrD does contain a cysteine residue at a different location (C441). However, experiments with $E$. coli UvrD showed no effect on oligomeric state with changes in redox potential (Fig. S7).

Another pathway for stimulation of unwinding by UvrD-family enzymes requires the binding of activating partners. The mismatch-repair protein MutL can activate the monomer helicase activity of $E$. coli UvrD as well as stimulate the activity of UvrD dimers and activation is accompanied by a change in the rotational state of the $2 \mathrm{~B}$ domain (33). This interaction also leads to enhanced processivity which enables UvrD to unwind longer stretches of DNA when functioning with MutL (32). Similarly, the accessory factor PriC can activate the Rep monomer helicase and stimulate the Rep dimer helicase (76). By analogy, the NHEJ factor, Mtb Ku, has been reported to bind to the Cterminal region of UvrD1 (45) suggesting a role for UvrD1 in double-strand-break repair (DSB). As the results from our study show that UvrD1 can exist as a monomer or dimer depending on the redox potential, we are currently investigating whether Ku can activate the UvrD1 monomer helicase and/or stimulate dimer activity and whether it does this via modulation of the $2 \mathrm{~B}$ domain conformation.

Mtb actually has two UvrD-family members in its genome, UvrD1 and UvrD2, with UvrD1 being the homologue to $E$. coli UvrD $(45-47,77)$ and UvrD2 consisting of an N-terminal SF1 helicase motor linked to an HRDC (helicase and Rnase D C-terminal) domain and tetracysteine motif domains $(44,78)$. The cysteines within the tetracysteine motif bind zinc and the domain is 
required for helicase activity of UvrD2 in vitro (44). However, in this case the activity appears to be dependent on the presence of the domain and not the presence of the individual cysteines themselves. Interestingly, while WT UvrD2 does not show a dependence on $\mathrm{Ku}$, a truncated construct lacking the tetracysteine domain can be activated by Ku (44). Therefore, while both UvrD1 and UvrD2 utilize cysteine residues for helicase activity, they do so via distinct biochemical mechanisms.

During infection, Mtb resides within alveolar macrophages and neutrophils where it is exposed to reactive oxygen species (ROI) and reactive nitrogen intermediates (RNI) that cause DNA damage $(49,79,80)$. Mtb lacks mismatch repair (81) and the response of $M$ tb to these insults likely involves NER pathways (79). During NER, UvrD1 unwinds the damaged DNA strand to remove bulky lesions that have been recognized by UvrA/UvrB and excised by UvrC (2). Analysis of gene expression data have shown UvrA to be highly expressed during oxidative stress (82). In addition, both $u v r D 1 / u v r B$ and $u v r D 1 / u v r A$ double mutants in M. smegmatis have been shown to be more sensitive to tertiary butyl hydroperoxide and acidified nitrite than wild-type strains $(46,83)$. All of these observations suggest a role of NER enzymes, including UvrD1, during oxidative stress in Mtb. This is distinct from E. coli, in which repair of RNI and ROI-induced DNA damage is accomplished by base-excision repair and homologous recombination (84). Thus, the redox dependent dimerization of UvrD1 we report here may represent an important mechanism in Mtb underlying the repair of oxidative-dependent DNA damage during infection.

\section{Materials and Methods}

Cloning, overexpression, and purification of Mycobacterium tuberculosis UvrD1: Mtb UvrD1 (Rv0949) from H37Rv was cloned in the expression vector pET with SUMO-His tag at the Nterminus and Kannamycin resistance. It was PCR amplified with BamH1 at the 5' and Hindlll at the 3'end. UvrD1 2B domain cysteine to alanine substitution and 1A1B double cysteine to threonine substitution mutations were introduced into the Mtb UvrD1 plasmid by PCR amplification using primers and site directed mutagenesis kit Agilent product 200521. Sequences for all primers and a list of plasmids can be found in Supplemental Table 5. The inserts of all UvrD1 plasmids were sequenced to exclude the acquisition of unwanted coding changes during amplification or cloning. The pET-Mtb UvrD1 plasmids were transformed into Escherichia coli BL21(DE3). Cultures (3 L) were grown at $37{ }^{\circ} \mathrm{C}$ in a Luria-Bertani medium containing $50 \mathrm{mg} / \mathrm{ml}$ kanamycin until the $A_{600}$ reached $\sim 0.5$. The cultures were chilled on ice for about 1 hour, and the expression of recombinant protein was induced around $0.55 \mathrm{OD}$ with $0.25 \mathrm{mM}$ isopropyl- $\beta$-D-thiogalactopyranoside (IPTG), followed by incubation at $16{ }^{\circ} \mathrm{C}$ for $16 \mathrm{~h}$ with constant shaking. The cells were harvested by centrifugation, and the pellets were either stored at $-80^{\circ} \mathrm{C}$ or used for subsequent procedures that were performed at $4{ }^{\circ} \mathrm{C}$. The bacterial cells from the 3-liter culture were resuspended in $50-75 \mathrm{ml}$ of lysis buffer ( $50 \mathrm{mM}$ Tris- $\mathrm{HCl}, \mathrm{pH} 7.5,0.25 \mathrm{M} \mathrm{NaCl}, 10 \%$ sucrose). Lysozyme and Triton X-100 were added to final concentrations of $1 \mathrm{mg} / \mathrm{ml}$ and $0.1 \%$, respectively. At the time of lysis, a complete EDTA-free protease inhibitor cocktail (Sigma: product 118735800) was added to the lysate. Next the lysates were sonicated and insoluble material was removed by centrifugation at $14 \mathrm{~K}$ for 45 minutes. The soluble extracts were applied to 2-ml columns of nickel-nitrilotriacetic acidagarose (Ni-NTA) (QIAGEN catalog no. 30210) that had been equilibrated with lysis buffer without protease inhibitors. The columns were washed with 10X column volume of wash buffer $(50 \mathrm{mM}$ Tris- $\mathrm{HCl}, \mathrm{pH} 8.0,0.25 \mathrm{M} \mathrm{NaCl}, 0.05 \%$ Triton X-100, $10 \%$ glycerol) and then eluted stepwise with wash buffer containing 50,100, 200,500, and $1000 \mathrm{mM}$ imidazole. The polypeptide compositions of the column fractions were monitored by SDS-PAGE. The his-SUMO-tagged UvrD1 polypeptides were recovered predominantly in the 100 - and $200-\mathrm{mM}$ imidazole eluates. Fractions containing the UvrD1 protein were pooled and His-tagged Ulp1 protease was added (at a ratio of 1:500 wt/wt protease per protein) and dialyzed against dialysis buffer $(50 \mathrm{mM}$ Tris- $\mathrm{HCl}, \mathrm{pH} 8.0,1 \mathrm{mM}$ EDTA, $0.1 \%$ Triton X-100, 10\% glycerol) containing $150 \mathrm{mM} \mathrm{NaCl}$ overnight. The SUMO-cut UvrD1 was then incubated with Ni-NTA agarose for about 3 hours and the untagged UvrD1 (cleaved) was recovered in the flow-through and wash fractions. After pooling and concentrating the fractions by VIVASPIN centrifugal filters (30 kDa cutoff: product Sartorius VS2021), the protein was loaded on 
heparin HiTRAP column (Cytiva: product 17040701) (5 ml x 2) pre-equilibrated with dialysis buffer containing $150 \mathrm{mM} \mathrm{NaCl}$. Upon running a linear gradient from 200 to $800 \mathrm{mM} \mathrm{NaCl}$, the protein eluted at approximately $400 \mathrm{mM} \mathrm{NaCl}$. The fractions with a single band on a reducing SDS-PAGE corresponding to the molecular weight of a monomer were pooled together and concentrated to load on the S300 sizing column (HiPrep 16/60 Sephacryl S-300 HR column,Cytvia, product 17116701 ) in buffer $150 \mathrm{mM} \mathrm{NaCl}, 10 \%$ glycerol and TRIS pH 8.0 at $25^{\circ} \mathrm{C}$ without DTT. The peak fractions were pooled and stored in $-80^{\circ} \mathrm{C}$ at concentrations about $15-20 \mu \mathrm{M}$. Both the $2 \mathrm{~B}$ mutant and $1 \mathrm{~A} 1 \mathrm{~B}$ double mutant were overexpressed and purified in a manner similar to the wild-type UvrD1 protein.

Homology Modeling of Mtb UvrD1: The predicted structure of Mtb UvrD1 was obtained using PHYRE2 (85) by submitting the amino acid sequence of Mtb UvrD1. The PDB reference used for modeling open structure of Mtb UvrD1 was E. coli UvrD was 3LFU and for modeling closed structure is $B$. stearothermophilus PcrA helicase complex 3PJR and methods for SASA calculations done in Chimera (53).

Phylogeny analysis of Mtb UvrD1: The protein sequence of Mtb UvrD1 obtained from uniprot (https://www.uniprot.org/uniprot/P9WMQ1.fasta) was used to Blast against various genus and species of classes of Phylum Actinobacteria (https://blast.ncbi.nlm.nih.gov/Blast.cgi). Two-three genus of orders in which the cysteine in $2 \mathrm{~B}$ domain is conserved were chosen and aligned in Clustal omega (86) and the phylogenetic tree was plotted using NJ plot (87).

Analytical Size Exclusion Chromatography: $1 \mathrm{~mL}$ of $\mathrm{Mtb}$ UvrD1 $(30 \mu \mathrm{M})$ was injected in a S300 gel filtration column at a flow rate of $0.25 \mathrm{~mL} / \mathrm{min}$, monitoring absorbance at $280 \mathrm{~nm}$ for a measure of the elution volume $(V)$ in buffer $150 \mathrm{mM} \mathrm{NaCl}, 10 \%$ glycerol and TRIS $\mathrm{pH} 8.0$. The value of $V_{\mathrm{e}} / V_{\circ}$ was interpolated using the generated standard curve (Bio-Rad gel filtration standard; product \#1511901) to yield the estimated molecular weight of Mtb UvrD1 monomer $90 \mathrm{kDa}$ and dimer 170 $\mathrm{kDa}$ fractions.

DNA Substrates: Single stranded DNA which are either labeled with Cy5, Cy3, FAM or BHQ2 were ordered from IDT. For annealing of the oligos the Cy5 labeled at 5'end of the single stranded DNA was mixed with an equimolar concentration of unlabeled complementary strand or complementary strand labeled with $\mathrm{BHQ} 2$ in $10 \mathrm{mM}$ Tris $\mathrm{pH} 8.0,50 \mathrm{mM} \mathrm{NaCl}$, followed by heating to $95^{\circ} \mathrm{C}$ for five minutes and slow cooling to room temperature.

Synthesis of poly-dT: The homodeoxypolynucleotide, poly-dT substrate was used to measure dissociation rate from internal sites of ssDNA. Since the poly-dT from commercial sources is polydisperse, we prepared samples using enzyme terminal deoxynucleotidyl transferase (TdTase) from calf thymus gland to catalyze polymerization of deoxynucleotide triphosphate into poly-dT of more well-defined lengths (88). The protocol includes mixing dT(100) with potassium cacodylate buffer, potassium chloride, Cobalt chloride, Inorganic pyrophosphatase (ThermoFisher Scientific \#EF0221), deoxythymidine-5'-triphosphate dTTP (ThermoFisher Scientific \#R0171) and terminal deoxynucleotidyl transferase (TdTase ThermoFisher Scientific \#10533065). The reaction was kept at room temperature for 3-4 days and poly-dT was purified using phenol chloroform extraction and suspending the air-dried pellet in water. The weight average length of the poly-dT was determined by measuring the weight average sedimentation coefficient by boundary sedimentation velocity experiments using AUC. The weight average length determined from this method is 964 nucleotides and was determined using method from the measured weight average sedimentation coefficient on poly-U (89). 
Analytical ultracentrifugation: The analytical ultracentrifugation sedimentation velocity experiments were performed using a Proteome Lab XL-A analytical ultracentrifuge equipped with an An50Ti rotor (Beckman Coulter, Fullerton, CA). The sample $(380 \mu \mathrm{l})$ and buffer $(410 \mu \mathrm{l})$ were loaded into each sector of an Epon charcoal-filled two-sector centerpiece. All experiments were performed at $25^{\circ} \mathrm{C}$ and $42,000 \mathrm{rpm}$. Absorbance data were collected by scanning the sample cells at intervals of $0.003 \mathrm{~cm}$, monitoring either at $230 \mathrm{~nm}$ or $280 \mathrm{~nm}$ depending on protein concentration to maintain an absorbance signal between 0.1 and 1 . Both the DNA and protein samples were dialyzed in buffer $75 \mathrm{mM} \mathrm{NaCl}, 20 \%$ glycerol and $10 \mathrm{mM}$ TRIS pH 8.0 except the salt titration where the protein was dialyzed in different salts at $20 \%$ glycerol at $10 \mathrm{mM}$ TRIS pH 8.0.

Continuous sedimentation coefficient distributions, $c(s)$, were calculated using SEDFIT(6), truncating the fit at 7.0 radial position to avoid contributions of glycerol buildup (90). This analysis yielded individual sedimentation coefficients for each monomer, dimer, and tetramer species as well as a weighted average frictional coefficient $\left(f / f_{\circ}\right)$ for the entire distribution (Table S1). Calculated sedimentation coefficients were converted to $20^{\circ} \mathrm{C}$ water conditions $\left(s_{20, w}\right)$ according to:

$$
s_{20, w}=s_{\exp } \frac{\eta_{\exp }}{\eta_{20, w}}\left(\frac{1-\bar{v}_{20} \rho_{20, w}}{1-\bar{v}_{\exp } \rho_{\exp }}\right)
$$

where $\rho_{20, w}$ and $\eta_{20, w}$ are density and viscosity of water at $20^{\circ} \mathrm{C}, \rho_{\exp }$ and $\eta_{\exp }$ are density and viscosity of the buffer at the experimental temperature of $25^{\circ} \mathrm{C}$, and $\bar{v}_{20}$ and $\bar{v}_{\text {exp }}$ are partial specific volumes of the protein at $20^{\circ} \mathrm{C}$ and at $25^{\circ} \mathrm{C}$. Buffer densities, $\left(\rho_{\exp }\right)$ and viscosities $\left(\eta_{\text {exp }}\right)$ were calculated from buffer composition using SEDNTERP (91). Partial specific volumes $\left(\bar{v}_{\text {exp }}\right)$ for $M t b$ UvrD1 and point mutations were calculated in SEDNTERP using the amino acid composition. Integration of the entire c(s) distribution vs. the integration of an individual sedimentation species was performed and used to calculate the population fraction (92).

For AUC experiments done in the presence of Cy5 labeled DNA, the absorbance signal was collected by scanning the sample cells at $650 \mathrm{~nm}$. Partial specific volumes $\left(\bar{v}_{\text {exp }}\right)$ for labeled DNA and the UvrD1-DNA complex were calculated according to:

$$
\bar{v}=\frac{\left(\sum_{i=1}^{n} n_{i} M_{i} \bar{v}_{i}\right)}{\sum_{i=1}^{n} n_{i} M_{i}}
$$

For AUC experiments conducted at different redox potentials, the protein was first dialyzed in Buffer A with $75 \mathrm{mM} \mathrm{NaCl}$ and then $1 \mathrm{mM}$ DTT was added at a respective concentration and then titrated with a range of $\mathrm{H}_{2} \mathrm{O}_{2}$ from 0.5 to $2 \mathrm{mM}$. Redox potential was measured via Metler Toledo Redox micro electrode product \#UX-35902-33. After $\mathrm{H}_{2} \mathrm{O}_{2}$ treatment protein was incubated at room temperature for two hours before performing AUC.

Stopped-flow double-stranded (ds) DNA unwinding assay: All stopped-flow experiments were carried out at $25^{\circ} \mathrm{C}$ using an Applied Photo physics instrument SX-20, total shot volume $100 \mu \mathrm{l}$, dead time $1 \mathrm{~ms}$. All experiments were carried out in Buffer with TRIS pH 8.0, $75 \mathrm{mM} \mathrm{NaCl}$, and $20 \%$ glycerol in the absence or presence of $1 \mathrm{mM}$ DTT. Cy5 fluorophore was excited using $625 \mathrm{~nm}$ LED (Applied Photo physics Ltd., Leatherhead, UK) and its fluorescence emission was monitored at wavelengths $>665 \mathrm{~nm}$ using a long-pass filter (Newport Optics). The traces represent the average of 5 independent shots and at least two different protein purifications. In this assay, a double-stranded 18-basepair DNA with a T20/T10 tail with Cy5 fluorophore is attached to the long strand and the black hole quencher (BHQ_2) attached to the short strand (Supplemental Table 6). The concentrations mentioned are the final after mixing the contents of both syringes. UvrD1 $(200 \mathrm{nM})$ is incubated with $2 \mathrm{nM}$ DNA in one syringe which is then rapidly mixed with the contents in another syringe that consists of (TRAP a complementary DNA strand in excess protein (25X, 5 
$\mu \mathrm{M}), \mathrm{Mg}^{+2}(5 \mathrm{mM})$, and ATP $(1 \mathrm{mM})$. The concentrations of ATP and $\mathrm{Mg}^{+2}$ used were determined to be optimal for Mtb UvrD1 unwinding assays (48). DNA strand separation is accompanied by an increase in the fluorescence signal. The unwinding signal is normalized to the signal from positive and negative control to get fraction of DNA unwound. The positive control is $2 \mathrm{nM}$ double stranded DNA with BHQ2 on the short and Cy5 on the long strand that is denatured in the presence of TRAP and $200 \mathrm{nM}$ UvrD1 is added at room temperature to get maximum fluorescence signal. The negative control is the average fluorescence value recorded for the fully annealed DNA ( $2 \mathrm{nM})$ with UvrD1 (200 nM) shot against buffer alone. To get DNA unwinding with a change in redox potential the protein was dialyzed treated with DTT and titrated with $\mathrm{H}_{2} \mathrm{O}_{2}$ in similar way as done for AUC experiments and incubated with DNA. This protein DNA mix was then used for unwinding experiments.

Stopped flow single stranded (ss) DNA translocation assays: The kinetics of UvrD1 monomer and dimer translocation was examined in a stopped-flow experiment by monitoring the arrival of UvrD1 of a series of oligodeoxythymidylates length $(L=20,35,45,64,75,94$, and 104) nucleotides labeled at the 5 '-end with Cy3 (Supplemental Table 6) (62). Cy3 fluorescence was excited using a 535 $\mathrm{nm}$ LED with a $550 \mathrm{~nm}$ short-pass cut-off filter and emission was monitored at $>570 \mathrm{~nm}$ using a long-pass filter (Newport Optics). UvrD1 was pre-incubated with ssDNA in one syringe and reactions were initiated by $1: 1$ mixing with $1 \mathrm{mM} \mathrm{ATP,} 5 \mathrm{mM} \mathrm{MgCl}_{2}$ and heparin at a concentration of $1 \mathrm{mg} / \mathrm{ml}$ to prevent rebinding of UvrD1 $(50 \mathrm{nM})$ to DNA (100 nM). Excess DNA to UvrD1 ratio was used to prevent binding of more than one UvrD1 monomer on DNA (62). Global analysis of time courses using the n-step sequential model was done to calculate various translocation parameters. For making heparin solution to be used as a TRAP for protein ensuring single round conditions, heparin sodium salt (porcine intestinal mucosa, Millipore Sigma \#H3393) was dialyzed into Buffer A plus $75 \mathrm{mM} \mathrm{NaCl}$ and concentrations were determined by an Azure A standard curve (93).

Tryptophan fluorescence-based dissociation kinetics: Dissociation kinetics of UvrD1 were monitored by the increase in UvrD1 tryptophan fluorescence, excited using a $290 \mathrm{~nm}$ LED (Applied Photophysics Ltd., Leatherhead, UK) and monitoring emission at $>305 \mathrm{~nm}$ using a long-pass filter (check if this is from Newport or AP). The observed dissociation rate from internal ssDNA sites for UvrD1 monomer (with $1 \mathrm{mM}$ DTT) and dimer (no DTT) was measured using (dT) ${ }_{100}$ and poly(dT) oligos (average length of 964 nucleotides; see synthesis of poly-dT section), respectively. In one syringe UvrD1 (100 nM) was added with DNA $(50 \mathrm{nM})$ (concentrations listed are after equal volume mixing). In another syringe ATP, $\mathrm{MgCl}_{2}$ and heparin were added at the same concentrations as translocation assays and the observed dissociation kinetic traces were best fit to a single exponential using ProData Viewer (Applied Photophysics). All experiments were performed at 25 ${ }^{\circ} \mathrm{C}$ in Buffer $\mathrm{A}$ with $75 \mathrm{mM} \mathrm{NaCl}$ and represent the average of 5 independent shots (88).

ssDNA translocation and unwinding fitting analysis: The translocation and the unwinding data was fit using the code from https://github.com/ordabayev/global-fit and unwinding and translocation rates are calculated. Globalfit is a wrapper around Imfit https://Imfit.github.io/lmfit-py/ providing an interface for multiple curves fitting with global parameters. Python 3 is installed via Anaconda along with modules like numpy, scipy, matpotlib, Imfit, emcee, corner, os and pandas and then globalfit model is used to fit the data for unwinding using n-step unwinding model and translocation using a two-step dissociation model (64).

Steady-State Anisotropy Measurements: All fluorescence titrations were performed using a spectrofluorometer (ISS, Champaign, IL) equipped with Glan-Thompson polarizers. Measurements of the anisotropy and total fluorescence intensity of FAM-labeled double stranded DNA 18bp with T20 single stranded tail were recorded using excitation and emission wavelengths of 490 and 522 $\mathrm{nm}$, respectively, using 


$$
\mathrm{r}=\frac{I_{V V}-G I_{V H}}{I_{V V}+2 G I_{V H}}
$$

where $I_{\text {TOT }}=I_{\mathrm{VV}}+2 G I_{\mathrm{VH}}$ and $G$ is the $G$ factor (94). The recorded value of $G$ factor remained between 0.85 to .9 throughout the titrations. Titrations were performed using a Starna cells cuvette catalog number $16.100 \mathrm{~F}-\mathrm{Q}-10 / \mathrm{Z} 15$ with dimensions $12.5 \times 12.5 \times 45 \mathrm{~mm}$ and pathlength $1 \mathrm{~cm}$. The protein was mixed 3-4 times with DNA during titrations and let it sit for 5 minutes before recording anisotropy values. The total volume of added protein was $30 \%$ of the initial volume and as a control the dilution with buffer of up-to $30 \%$ for DNA alone sample did not change the anisotropy value of the DNA. All titrations were conducted in Buffer $A$ at $25^{\circ} \mathrm{C}$ in $75 \mathrm{mM} \mathrm{NaCl}$. The data represents average from three independent experiments for WT-DTT and 2 independent experiments for the 2B mutant.

\section{Acknowledgments}

This work was supported by NIH R01 GM134362 to EAG, NIH R35 GM136632 to TML, and by NIH T32 AI007172 to AC. The content is solely the responsibility of the authors and does not necessarily represent the official views of the National Institutes of Health. 


\section{References}

1. A. Sancar, DNA Excision Repair. Annu Rev Biochem 65, 43-81 (1996).

2. Y. Peng, H. Wang, L. Santana-Santos, C. Kisker, B. van Houten, "Nucleotide Excision Repair from Bacteria to Humans: Structure-Function Studies" in Chemical Carcinogenesis., (2011), pp. 267-296.

3. C. Kisker, J. Kuper, B. van Houten, Prokaryotic nucleotide excision repair. Csh Perspect Biol 5, a012591-a012591 (2013).

4. K. Howan, et al., Initiation of transcription-coupled repair characterized at singlemolecule resolution. Nature 490, 1-4 (2012).

5. A. J. Smith, N. J. Savery, RNA polymerase mutants defective in the initiation of transcription-coupled DNA repair. Nucleic Acids Res 33, 755-764 (2005).

6. B. Pani, E. Nudler, Mechanistic insights into transcription coupled DNA repair. Dna Repair 56, 42-50 (2017).

7. V. Kamarthapu, E. Nudler, Rethinking transcription coupled DNA repair. Curr Opin Microbiol 24, 15-20 (2015).

8. G. Kokic, et al., Structural basis of TFIIH activation for nucleotide excision repair. Nat Commun 10, 2885 (2019).

9. V. Oksenych, B. B. de Jesus, A. Zhovmer, J. M. Egly, F. Coin, Molecular insights into the recruitment of TFIIH to sites of DNA damage. Embo J 28, 2971-2980 (2009).

10. E. Compe, J. M. Egly, TFIIH: when transcription met DNA repair. Nat Rev Mol Cell Bio 13, 343-354 (2012).

11. R. R. Iyer, A. Pluciennik, V. Burdett, P. L. Modrich, DNA Mismatch Repair:

Functions and Mechanisms. Chem Rev 106, 302-323 (2006).

12. C. Bruand, S. D. Ehrlich, UvrD-dependent replication of rolling-circle plasmids in Escherichia coli. Mol Microbiol 35, 204-210 (2000).

13. G. F. Moolenaar, C. Moorman, N. Goosen, Role of the Escherichia coli Nucleotide Excision Repair Proteins in DNA Replication. J Bacteriol 182, 5706-5714 (2000).

14. M. Florés, N. Sanchez, B. Michel, A fork-clearing role for UvrD. Mol Microbiol 57, 1664-1675 (2005). 
15. R. C. Heller, K. J. Marians, Non-replicative helicases at the replication fork. Dna Repair 6, 945-952 (2007).

16. H. M. Arthur, R. G. Lloyd, Hyper-recombination in uvrD mutants of Escherichia coli K-12. Mol Gen Genetics Mgg 180, 185-191 (1980).

17. X. Veaute, et al., UvrD helicase, unlike Rep helicase, dismantles RecA nucleoprotein filaments in Escherichia coli. Embo J 24, 180-189 (2005).

18. V. Petrova, et al., Active displacement of RecA filaments by UvrD translocase activity. Nucleic Acids Res 43, 4133-4149 (2015).

19. T. M. Lohman, E. J. Tomko, C. G. Wu, Non-hexameric DNA helicases and translocases: mechanisms and regulation. Nat Rev Mol Cell Bio 9, 391-401 (2008).

20. K. D. Raney, A. K. Byrd, S. Aarattuthodiyil, DNA Helicases and DNA Motor Proteins. Adv Exp Med Biol 767, 17-46 (2012).

21. M. S. Dillingham, D. B. Wigley, M. R. Webb, Demonstration of Unidirectional Single-Stranded DNA Translocation by PcrA Helicase: Measurement of Step Size and Translocation Speed. Biochemistry-us 39, 205-212 (1999).

22. M. S. Dillingham, D. B. Wigley, M. R. Webb, Direct Measurement of SingleStranded DNA Translocation by PcrA Helicase Using the Fluorescent Base Analogue 2Aminopurine. Biochemistry-us 41, 643-651 (2001).

23. N. K. Maluf, C. J. Fischer, T. M. Lohman, A Dimer of Escherichia coli UvrD is the active form of the helicase in vitro. J Mol Biol 325, 913-935 (2003).

24. E. J. Tomko, C. J. Fischer, A. Niedziela-Majka, T. M. Lohman, A nonuniform stepping mechanism for E. coli UvrD monomer translocation along single-stranded DNA. Mol Cell 26, 335-347 (2007).

25. A. Niedziela-Majka, M. A. Chesnik, E. J. Tomko, T. M. Lohman, Bacillus stearothermophilus PcrA monomer is a single-stranded DNA translocase but not a processive helicase in vitro. J Biol Chem 282, 27076-27085 (2007).

26. N. K. Maluf, T. M. Lohman, Self-association Equilibria of Escherichia coli UvrD Helicase Studied by Analytical Ultracentrifugation. J Mol Biol 325, 889-912 (2003).

27. K. S. Lee, H. Balci, H. Jia, T. M. Lohman, T. Ha, Direct imaging of single UvrD helicase dynamics on long single-stranded DNA. Nat Commun 4, 1878 (2013).

28. K. M. Brendza, et al., Autoinhibition of Escherichia coli Rep monomer helicase activity by its 2B subdomain. P Natl Acad Sci Usa 102, 10076-10081 (2005). 
29. S. Arslan, R. Khafizov, C. D. Thomas, Y. R. Chemla, T. Ha, Engineering of a superhelicase through conformational control. Science 348, 344-347 (2015).

30. B. Nguyen, Y. Ordabayev, J. E. Sokoloski, E. Weiland, T. M. Lohman, Large domain movements upon UvrD dimerization and helicase activation. Proc National Acad Sci 114, 12178-12183 (2017).

31. M. J. Comstock, et al., Direct observation of structure-function relationship in a nucleic acid-processing enzyme. Science 348, 352-354 (2015).

32. M. A. Makurath, K. D. Whitley, B. Nguyen, T. M. Lohman, Y. R. Chemla, Regulation of Rep helicase unwinding by an auto-inhibitory subdomain. Nucleic Acids Res 47, 2523-2532 (2019).

33. Y. A. Ordabayev, B. Nguyen, A. Niedziela-Majka, T. M. Lohman, Regulation of UvrD Helicase Activity by MutL. J Mol Biol 430, 4260-4274 (2018).

34. Y. A. Ordabayev, B. Nguyen, A. G. Kozlov, H. Jia, T. M. Lohman, UvrD helicase activation by MutL involves rotation of its 2B subdomain. Proc National Acad Sci 116, 16320-16325 (2019).

35. E. J. Gwynn, et al., The conserved C-terminus of the PcrA/UvrD helicase interacts directly with RNA polymerase. PloS one 8, e78141 (2013).

36. K. Sanders, et al., The structure and function of an RNA polymerase interaction domain in the PcrA/UvrD helicase. Nucleic Acids Res 45 (2017).

37. V. Epshtein, et al., UvrD facilitates DNA repair by pulling RNA polymerase backwards. Nature 505, 372 (2014).

38. W. H. Organization, Global TB Report 2020 (2020).

39. D. Jensen, A. R. Manzano, J. Rammohan, C. L. Stallings, E. A. Galburt, CarD and RbpA modify the kinetics of initial transcription and slow promoter escape of the Mycobacterium tuberculosis RNA polymerase. Nucleic Acids Research 47, 6685-6698 (2019).

40. H. Boyaci, R. M. Saecker, E. A. Campbell, Transcription initiation in mycobacteria: a biophysical perspective. Biochem Soc Symp, 1-13 (2019).

41. C. Bertrand, A. Thibessard, C. Bruand, F. Lecointe, P. Leblond, Bacterial NHEJ: a never ending story. Mol Microbiol 111, 1139-1151 (2019).

42. J. Chen, H. Boyaci, E. A. Campbell, Diverse and unified mechanisms of transcription initiation in bacteria. Nat Rev Microbiol 19, 95-109 (2021). 
43. R. Hershberg, et al., High Functional Diversity in Mycobacterium tuberculosis Driven by Genetic Drift and Human Demography. Plos Biol 6, e311 (2008).

44. K. M. Sinha, N. C. Stephanou, M.-C. Unciuleac, M. S. Glickman, S. Shuman, Domain requirements for DNA unwinding by mycobacterial UvrD2, an essential DNA helicase. Biochemistry-us 47, 9355-9364 (2008).

45. K. M. Sinha, N. C. Stephanou, F. Gao, M. S. Glickman, S. Shuman, Mycobacterial UvrD1 is a $\mathrm{Ku}$-dependent DNA helicase that plays a role in multiple DNA repair events, including double-strand break repair. J Biol Chem 282, 15114-15125 (2007).

46. K. M. Sinha, M. S. Glickman, S. Shuman, Mutational analysis of Mycobacterium UvrD1 identifies functional groups required for ATP hydrolysis, DNA unwinding, and chemomechanical coupling. Biochemistry 48, 4019-4030 (2009).

47. J. Houghton, et al., Important role for Mycobacterium tuberculosis UvrD1 in pathogenesis and persistence apart from its function in nucleotide excision repair. $J$ Bacteriol 194, 2916-2923 (2012).

48. E. Curti, S. J. Smerdon, E. O. Davis, Characterization of the Helicase Activity and Substrate Specificity of Mycobacterium tuberculosis UvrD $\nabla$. J Bacteriol 189, 1542 1555 (2007).

49. H. T. Pacl, V. P. Reddy, V. Saini, K. C. Chinta, A. J. C. Steyn, Host-pathogen redox dynamics modulate Mycobacterium tuberculosis pathogenesis. Pathog Dis 76 (2018).

50. M. Mehta, A. Singh, Mycobacterium tuberculosis WhiB3 maintains redox homeostasis and survival in response to reactive oxygen and nitrogen species. Free Radical Bio Med 131, 50-58 (2018).

51. S. Upadhyay, E. Mittal, J. A. Philips, Tuberculosis and the art of macrophage manipulation. Pathog Dis 76 (2018).

52. P. Schuck, Size-Distribution Analysis of Macromolecules by Sedimentation Velocity Ultracentrifugation and Lamm Equation Modeling. Biophys J 78, 1606-1619 (2000).

53. E. F. Pettersen, et al., UCSF Chimera-A visualization system for exploratory research and analysis. J Comput Chem 25, 1605-1612 (2004).

54. H. Sowani, M. Kulkarni, S. Zinjarde, V. Javdekar, The Microbiology of Skin, Soft Tissue, Bone and Joint Infections. 105-121 (2017).

55. M. Goodfellow, A. L. Jones, Bergey's Manual of Systematics of Archaea and Bacteria. 1-14 (2020). 
56. A. Gupta, A. N. Ananthakrishnan, Economic burden and cost-effectiveness of therapies for Clostridiodes difficile infection: a narrative review. Ther Adv Gastroenter 14, 175628482110186 (2021).

57. P.-J. Chiu, et al., Clostridioides difficile spores stimulate inflammatory cytokine responses and induce cytotoxicity in macrophages. Anaerobe 70, 102381 (2021).

58. W. Cheng, J. Hsieh, K. M. Brendza, T. M. Lohman, E. coli Rep oligomers are required to initiate DNA unwinding in vitro11Edited by D. Draper. J Mol Biol 310, 327$350(2001)$.

59. S. A. E. Marras, F. R. Kramer, S. Tyagi, Efficiencies of fluorescence resonance energy transfer and contact-mediated quenching in oligonucleotide probes. Nucleic Acids Res 30, e122-e122 (2002).

60. J. A. Ali, T. M. Lohman, Kinetic Measurement of the Step Size of DNA Unwinding by Escherichia coli UvrD Helicase. Science 275, 377-380 (1997).

61. C. G. Wu, C. Bradford, T. M. Lohman, Escherichia coli RecBC helicase has two translocase activities controlled by a single ATPase motor. Nat Struct Mol Biol 17, 12101217 (2010).

62. C. J. Fischer, N. K. Maluf, T. M. Lohman, Mechanism of ATP-dependent Translocation of E.coli UvrD Monomers Along Single-stranded DNA. J Mol Biol 344, 1287-1309 (2004).

63. E. J. Tomko, C. J. Fischer, T. M. Lohman, Single-Stranded DNA Translocation of E. coli UvrD Monomer Is Tightly Coupled to ATP Hydrolysis. J Mol Biol 418, 32-46 (2012).

64. A. L. Lucius, N. K. Maluf, C. J. Fischer, T. M. Lohman, General Methods for Analysis of Sequential "n-step" Kinetic Mechanisms: Application to Single Turnover Kinetics of Helicase-Catalyzed DNA Unwinding. Biophys J 85, 2224-2239 (2003).

65. H. S. Subramanya, L. E. Bird, J. A. Brannigan, D. B. Wigley, Crystal structure of a DExx box DNA helicase. Nature 384, 379-383 (1996).

66. S. Korolev, J. Hsieh, G. H. Gauss, T. M. Lohman, G. Waksman, Major Domain Swiveling Revealed by the Crystal Structures of Complexes of E. coli Rep Helicase Bound to Single-Stranded DNA and ADP. Cell 90, 635-647 (1997).

67. S. S. Velankar, P. Soultanas, M. S. Dillingham, H. S. Subramanya, D. B. Wigley, Crystal Structures of Complexes of PcrA DNA Helicase with a DNA Substrate Indicate an Inchworm Mechanism. Cell 97, 75-84 (1999). 
68. J. Y. Lee, W. Yang, UvrD Helicase Unwinds DNA One Base Pair at a Time by a Two-Part Power Stroke. Cell 127, 1349-1360 (2006).

69. H. Jia, et al., Rotations of the 2B Sub-domain of E. coli UvrD Helicase/Translocase Coupled to Nucleotide and DNA Binding. J Mol Biol 411, 633-648 (2011).

70. H. Yokota, Y. A. Chujo, Y. Harada, Single-Molecule Imaging of the Oligomer Formation of the Nonhexameric Escherichia coli UvrD Helicase. Biophys J 104, 924-933 (2013).

71. J. Park, et al., PcrA helicase dismantles RecA filaments by reeling in DNA in uniform steps. Cell 142, 544-555 (2010).

72. B. Sun, et al., Impediment of E. coli UvrD by DNA-destabilizing force reveals a strained-inchworm mechanism of DNA unwinding - SI. Embo J 27, 3279-3287 (2008).

73. P. Soultanas, M. S. Dillingham, P. Wiley, M. R. Webb, D. B. Wigley, Uncoupling DNA translocation and helicase activity in PcrA: direct evidence for an active mechanism. Embo J 19, 3799-3810 (2000).

74. M. R. Singleton, M. S. Dillingham, M. Gaudier, S. C. Kowalczykowski, D. B. Wigley, Crystal structure of RecBCD enzyme reveals a machine for processing DNA breaks. Nature 432, 187-193 (2004).

75. M. Wilkinson, Y. Chaban, D. B. Wigley, Mechanism for nuclease regulation in RecBCD. Elife 5, e18227 (2016).

76. B. Nguyen, M. K. Shinn, E. Weiland, T. M. Lohman, Regulation of E. coli Rep Helicase Activity by PriC. J Mol Biol 433, 167072 (2021).

77. P. Singh, et al., Mycobacterium tuberculosis UvrD1 and UvrA proteins suppress DNA strand exchange promoted by cognate and noncognate RecA proteins.

Biochemistry-us 49, 4872-4883 (2010).

78. A. Williams, et al., UvrD2 is essential in Mycobacterium tuberculosis, but its helicase activity is not required. $J$ Bacteriol 193, 4487-4494 (2011).

79. K. H. Darwin, C. F. Nathan, Role for Nucleotide Excision Repair in Virulence of Mycobacterium tuberculosis. Infect Immun 73, 4581-4587 (2005).

80. S. K. Matta, D. Kumar, Hypoxia and classical activation limits Mycobacterium tuberculosis survival by Akt-dependent glycolytic shift in macrophages. Cell Death Discov 2, 16022 (2016). 
81. B. Springer, et al., Lack of mismatch correction facilitates genome evolution in mycobacteria. Mol Microbiol 53, 1601-1609 (2004).

82. L. Cabusora, E. Sutton, A. Fulmer, C. V. Forst, Differential network expression during drug and stress response. Bioinformatics 21, 2898-2905 (2005).

83. C. Güthlein, et al., Characterization of the Mycobacterial NER System Reveals Novel Functions of the uvrD1 Helicase ${ }^{\nabla}$. J Bacteriol 191, 555-562 (2008).

84. J. A. Imlay, S. Linn, Mutagenesis and stress responses induced in Escherichia coli by hydrogen peroxide. J Bacteriol 169, 2967-2976 (1987).

85. L. A. Kelley, S. Mezulis, C. M. Yates, M. N. Wass, M. J. E. Sternberg, The Phyre2 web portal for protein modeling, prediction and analysis. Nat Protoc 10, 845-858 (2015).

86. F. Sievers, et al., Fast, scalable generation of high-quality protein multiple sequence alignments using Clustal Omega. Mol Syst Biol 7, 539 (2011).

87. G. Perrière, M. Gouy, WWW-query: An on-line retrieval system for biological sequence banks. Biochimie 78, 364-369 (1996).

88. E. Tomko, "Transient-state kinetic studies of Escherichia Coli UvrD monomer translocation along single-stranded DNA." (2010).

89. L. D. Inners, G. Felsenfeld, Conformation of polyribouridylic acid in solution. J Mol Biol 50, 373-389 (1970).

90. J. P. Gabrielson, K. K. Arthur, B. S. Kendrick, T. W. Randolph, M. R. Stoner, Common excipients impair detection of protein aggregates during sedimentation velocity analytical ultracentrifugation. J Pharm Sci 98, 50-62 (2009).

91. T. M. Laue, B. D. Shah, T. M. Ridgeway, S. L. Pelletier, "Computer-aided interpretation of analytical sedimentation data for proteins" in Analytical Ultracentrifugation in Biochemistry and Polymer Science, S. Harding, A. Rowe, J. Horton, Eds. (Royal Society of Chemistry, 1992), pp. 90-125.

92. J. Dam, P. Schuck, Calculating Sedimentation Coefficient Distributions by Direct Modeling of Sedimentation Velocity Concentration Profiles. Methods Enzymol 384, 185212 (2004).

93. D. P. Mascotti, T. M. Lohman, Thermodynamics of Charged Oligopeptide-Heparin Interactions. Biochemistry-us 34, 2908-2915 (1995).

94. J. R. Lakowicz, "Fluorescence Anisotropy" in Principles of Fluorescence Spectroscopy., (Springer US, 1999), pp. 291-319. 